19 - Tempo

\title{
I magens do corpo e saber médico em Portugal no século XVI ${ }^{* 1}$
}

\author{
Lígia B ellini**
}

0 artigo discute um conjunto de imagens e procedimentos analíticos pelos quais o corpo humano e suas partes são descritos e compreendidos em textos portugueses do século XVI, em especial tratados médicos. As representações investigadas envolvem o uso, por analogia, de imagens derivadas da experiência humana em geral. Procurando identificar diferentes usos do argumento analógico, busca-se iluminar as relações entre os autores e certas correntes intelectuais do período, entre elas o humanismo renascentista, o pensamento escolástico e abordagens mais associadas à observação empírica.

Palavras-chave: I magens do corpo - Saber M édico -P ortugal R enascentista.

I mages of the body and medical scholarship in sixteenth-century Portugal $T$ he article is concerned with a number of linguistic devices and analytical procedures by means of which the human body and its parts are described and explained in

\footnotetext{
* Artigo recebido em fevereiro de 2005 e aprovado para publicação em abril de 2005.

** Professora Adjunta do D epartamento de $\mathrm{H}$ istória da U niversidade F ederal da Bahia. D outora em H istória pela U niversidade de E ssex, I nglaterra. Research fellow no King's College (1998-1999) e no H eythrop College (2004 -2005), U niversidade de L ondres. E -mail: ligiabellini@uol.com.br

${ }^{1} \mathrm{O}$ presente artigo foi escrito com base em investigação financiada pelo CN Pq (com bolsas de doutorado e produtividade em pesquisa), durante pós-doutorado no H eythrop College, U niversidade de L ondres, financiado pela CAPE S. A tradução das fontes em latim e da bibliografia em língua estrangeira é de minha autoria. D evido a limitações de espaço, optei por não reproduzir aqui trechos da documentação no idioma original.
}

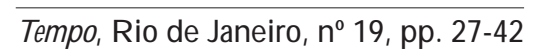


sixteenth-century Portuguese texts, particularly medical treatises. These representations involve the use, by analogical reasoning, of images derived from features of society or general human experience. I i is contended that the way thinkers rely on analogical argument can offer insight into their relationship with intellectual trends of the time, among them R enaissance humanism, scholasticism and the empirical current which emerged in the early modern period.

Key words: I mages of the body; M edical Scholarship; R enaissance P ortugal.

I mages du corps et savoir médical dans le Portugal du X V I è siècle

Cet article discute un ensemble d'images et de procédures analytiques par lesquels le corps humain et ses parties sont décrits et compris dans destextes portugais du XVIè siècle, en particulier dans des traités médicaux. $L$ es représentations étudiées incluent I'utilisation, par analogie, d'images dérivées de l'expérience humaine en général. E n essayant d'identifier différents usages du raisonnement par analogie, on cherche àéclairer les relations entre penseurs et courantsintellectuels de la période, notamment I'humanisme de la renaissance, la pensée scolastique et des approches plus fondées surl'observation empirique.

M ots-clefs : R eprésentations du Corps - Savoir M édical - P ortugal du XVI è siècle.

Procedimentos heurísticos e ilustrativos, como a analogia e a metáfora, tiveram importante papel na tradição de observação empírica, experimentação e quantificação, que se desenvolveu desde a Antigüidade até a É poca M oderna, conquanto se verifiquem, nesta trajetória, descontinuidades e mudanças significativas². Com respeito ao pensamento grego antigo, G eoffrey L loyd examina um grande número de exemplos em que objetos e fenômenos naturais, que não podiam ser observados através de método experimental direto, foram estudados e explicados por meio de analogia com objetos com os quais os pensadores tinham mai or familiaridade ${ }^{3}$. N as tradições científicas, este tipo de procedimento é, em geral, subordinado aos demais ní-

\footnotetext{
${ }^{2}$ Agnes Arber, "Anal ogy in the H istory of Science", M . F. A shley M ontagu (E d.), Studies and $\mathrm{E}$ ssays in the $\mathrm{H}$ istor y of $\mathrm{Scienceand} \mathrm{L}$ earning, Offered in $\mathrm{H}$ omageto $\mathrm{G}$ eor geSarton on the Occasion of his Sixtieth B irthday, N ew York, H enry Schuman, 1947, pp. 219-233; G eoffrey E . R. L loyd, Polarity and Analogy: T wo Types of Argumentation in E arly G reek Thought, $C$ ambridge, $C$ ambridge U niversity Press, 1966, "Part T wo"; B rian Vickers (E d.), 0 ccult and Scientific M entalities in the Renaissance, C ambridge, C ambridge U niversity Press, 1984, passim.

${ }^{3} \mathrm{P}$ ara exemplos relativos à investigação de aspectos da biologia humana, ver $\mathrm{P}$ olarity and Analogy, pp. 325-333 (E mpédocles); pp. 345-360 (autores do Corpus H ipocrático); pp. 366-380 (Aristóteles).
} 
veis do discurso, que são não-metafóricos, e claramente deles separado. $\mathrm{N}$ outras palavras, tradições científicas reconhecem a diferença entre argumento analógico e demonstração, e estão atentas para o fato de que objetos e fenômenos considerados semel hantes sob certos aspectos podem ser dissimilares sob outros. I sto se verifica no Renascimento e na ciência moderna a partir deste período e, conforme indicado por B rian Vickers, se observa já em pensadores antigos, como A ristóteles e Platão4.

E stas características do pensamento científico não se encontram sempre em textos médicos portugueses do século XVI. 0 presente artigo discute um conjunto de imagens e procedimentos analíticos pelos quais o corpo humano e suas partes são descritos e compreendidos nestes textos. As representações enfocadas envolvem o uso, por analogia, de imagens derivadas da experiência humana em geral. Sua análise ilumina as relações entre pensadores e correntes intelectuais do período, em especial quanto ao desenvolvimento de abordagens mais associadas à observação empírica. Com base em concepção originalmente proposta por L loyd, postula-se aqui que uma maior cautela no uso de argumento analógico corresponde a um maior desenvolvimento do empirismo no estudo do corpo. E ste autor propõe que a clarificação de certas relações lógicas (em particular as de similaridade e identidade, e os diferentes modos de oposição) ocorreu simultaneamente ao crescimento de uma "exigência de demonstrabilidade" no pensamento grego, dos primórdios até Aristóteles 5 .

U ma dificuldade com que o estudioso se depara, ao analisar tratados médicos portugueses sob esta perspectiva, está associada ao fato de que muitos dos artefatos lingüísticos neles utilizados provêm de outros textos, especial mente textos médicos antigos. I sto implica que, para entender o significado destes artefatos, é necessário considerar tanto a fonte original quanto o texto português em que se encontram. A tendência a "sacralizar" a linguagem, característica da tradição de exegese e comentário, dominante entre os pensadores estudados, tem como conseqüência que certas imagens não parecem particularmente significativas em relação ao imaginário social e cultural no contexto português do século XVI. Cautela especial é requerida na

${ }^{4}$ Vickers, "Analogy versus I dentity: the rejection of occult symbolism, 1580-1680", Vickers (E d.), Occult and Scientific M entalities..., op. cit., pp. 95-163.

${ }^{5} \mathrm{~L}$ loyd, Polarity and Analogy..., op. cit., esp. "Part T hree: Conclusion". 
análise deste tipo de representação e, muitas vezes, a proveniência parece ser a única questão a ser adequadamente proposta. D e qualquer forma, representações desta natureza constituem evidência de preeminência da tradição de comentário e da atitude a ela relacionada, de val orização do conhecimento antigo, entre os autores portugueses do período. Por outro lado, é necessário tentar compreender imagens encontradas nas fontes quinhentistas portuguesas em relação ao contexto cultural no qual elas circularam. Por esta razão, procura-se, neste artigo, também abordá-las em relação a "fatores semânticos", apontados por L . Jonathan Cohen e outros autores como aspectos que afetam o uso de palavras e noções: " convenção e motivação (...) significado emotivo, sinonimia, polisemia (...) e, transcendendo as fronteiras da linguagem (...) a 'atmosfera' geral, aspirações culturais e quadro moral peculiar da época" ${ }^{6}$. U ma forma de pôr isto em prática é comparar os textos médicos entre si e com outros tipos de escritos do período, inclusive literatura.

O utro aspecto a ser considerado preliminarmente diz respeito ao público ao qual os tratados estudados se dirigiam, uma vez que este, em geral, determina os modos de exposição nos textos. E xceto a R ecopilaçam deCirurgia, de Antonio da $\mathrm{Cruz}^{7}$, e a seção de medicina astrológica do R eportorio dos Tempos, de Valentim $\mathrm{F}$ ernandes ${ }^{8}$, endereçados a cirurgiões e outros praticantes da medicina fora do meio acadêmico, não fica claro como os textos médicos seriam utilizados. É certo, entretanto, que não se trata de manuais para uso de estudantes da área. Os prefácios e o arranjo interno dos tópicos discutidos sugerem que os tratados eram direcionados primeiramente aos sábios em medicina, grupo a que os próprios autores pertenciam, constituído de medici et philosophi, formados em cursos médicos na universidade, em geral também graduados em artes, com interesse no debate intelectual, incluindo medicina, ética, política, literatura, teologia e direito. Os tratados parecem ter sido escritos como contribuição a um universo amplo de discussão de questões inicialmente propostas pelas autoridades, e se estruturam de acordo com padrões de conteúdo e formas de exposição em geral adotados por pensadores formados na universidade?

\footnotetext{
${ }^{6} \mathrm{~L}$. J. C ohen, The Diversity of M eaning, L ondres, M ethuen, 1966, pp. 74-75.

${ }^{7} \mathrm{~L}$ isboa, M iguel D eslandes, 1688. Há edições anteriores, em 1601 e 1630.

${ }^{8} \mathrm{~L}$ isboa, 1563.

${ }^{9} \mathrm{D}$ iscussão mais circunstanciada dos pensadores médicos e seu contexto, em Portugal, no século XVI, encontra-se em L ígia B ellini, "M edicina e saber erudito em Portugal no R enascimento", E studos I bero-Americanos, vol. XXVII, n 1, Porto Alegre, 2001, pp. 43-74.
} 
M uitas das representações do corpo, encontradas em textos médicos portugueses, tiveram que ser, aqui, por razões de espaço, deixadas de lado. São discutidas a seguir apenas as imagens mais proeminentes, quanto à freqüência com que ocorrem e seu significado como expressão do universo intelectual da época.

0 debate em torno das funções do coração e do cérebro, no corpo humano, gerou uma série de imagens políticas, cuja análise revela um variado espectro de relações com as idéias de $\mathrm{G}$ al eno ${ }^{10}$, desta forma pondo em questão a caracterização, sem matizes, do saber médico do período simplesmente como "galênico". I magens do coração e do cérebro derivam principalmente da disputa relativa às opiniões de Galeno e Aristóteles quanto às funções e à importância destes órgãos. Tal disputa constituía uma das controvérsias centrais na medicina desde meados do século XIII, e era comum considerar-se que, junto com outras diferenças a propósito de aspectos da fisiologia humana, distinguia os "médicos" dos "filósofos"11. D e modo geral, os doutores portugueses endossavam a concepção galênica, contra Aristóteles, de que o cérebro era o centro dos sentidos e do movimento e, em certa medida, o órgão mais importante no corpo. Associado a isto, tinham como referência a idéia platônica e galênica de que o cérebro, o coração e o fígado eram, respectivamente, sedes das potências racional, espiritiva e apetitiva da alma, assim como das faculdades psíquica, vital e natural. N o entanto, quando se examinam representações do coração e do cérebro nos textos médicos, há uma certa inconsistência entre estas e o quadro brevemente apresentado acima. 0 coração é mais freqüentemente caracterizado utilizando-se imagens que sugerem posições de governo que o cérebro. Além disto, aquele é discutido mais extensivamente que este.

U m conjunto de imagens por meio das quais Antonio L uiz explica a relação entre estes dois órgãos expressa uma tentativa de reconciliar as opiniões de Galeno e Aristóteles quanto ao domínio sobre o movimento e os sentidos no corpo. E sta solução, comum na medicina dos finais da I dade M édia, consistia em introduzir "uma hierarquia conceitual na qual o cora-

\footnotetext{
${ }^{10} M$ édico grego que trabal hou em Roma no século II d.C. e a mais importante influência na medicina européia até o século XVII.

${ }^{11} \mathrm{~N}$ ancy $\mathrm{G}$. Siraisi, M edieval and $\mathrm{E}$ arly R enaissance M edicine, Chicago e $L$ ondres, U niversity of Chicago Press, 1990, pp. 80-81 e 107.
} 
ção governa o cérebro num sentido último ou filosófico, e o cérebro governa o sistema nervoso diretamente" ${ }^{12}$. L uiz compara o cérebro a um filho que, já tendo recebido herança do pai (a quem o coração é comparado), não mais depende das decisões paternas quanto ao que foi herdado; ou a um chefe militar que, após assumir o comando do exército, de acordo com determinações do rei (que corresponde ao coração, na analogia), não necessita mais das ordens deste; ou ao fogo que, depois de receber seu poder calorífico do céu (correspondendo ao coração), nada mais precisa deste último, para queimar madeira; ou a seres humanos que, tendo recebido poder reprodutivo do sol (o coração, na anal ogia) não necessitam dele receber qualquer outro poder para se reproduzirem ${ }^{13}$.

Conquanto sugira a adoção de uma concepção da medicina medieval, o conjunto de imagens acima parece ter sido inicialmente inspirado numa fonte que se tornou disponível apenas no Renascimento, De Placitis $H$ ippocratis et $P$ latonis, de Galeno. E ntretanto, tudo indica que o agrupamento das imagens na forma em que estão é da autoria de $L$ uiz. Além disto, o médico português endossa concepção dos estóicos à qual $G$ aleno se opõe, em De Placitis $\mathrm{H}$ ippocratis et Platonis. E ste último critica "todos os médicos e filósofos", particularmente os estóicos e, entre eles, Crisipo (c.279-206 a.C.), por acreditarem que o coração supria sensação e movimento ao cérebro. G aleno refere-se à opinião dos estóicos como a de que "o coração envia ao cérebro o começo da sensação e movimento, que então o cérebro fornece, através dos nervos, ao corpo como um todo; o cérebro é uma espécie de segunda fonte (...) comparável ao sátrapa do Grande R ei" ${ }^{14}$.

0 coração é representado como um rei diversas vezes, nos textos médicos portugueses. $N$ outra passagem de $D$ e R e M edica O pera, opondo-se à visão de Aristóteles de que o coração é o último órgão a morrer, L uiz compara o coração a um rei no comando de um exército. A sobrevivência ou derrota do rei numa batalha é tão importante para o exército como o coração é importante com respeito à vida ou à morte do corpo. Se o coração / rei sobreviver, o corpo se manterá vivo; se morrer, o resto do corpo morrerá15.

\footnotetext{
${ }^{12}$ Idem, pp. 81-82.

${ }^{13}$ De Re Medica Opera, Lisboa, L uís R odrigues, 1540, fol. 67v.

${ }^{14} \mathrm{G}$ aleno, $\mathrm{On}$ the D octrines of $\mathrm{H}$ ippocrates and P lato, E dição, tradução e comentário por Phillip de L acy, Berlim, Akademie-Verlag, 1980, 2 vols., L ivro II 6.13-15, p. 151.

${ }^{15}$ De Re M edica..., op. cit., fol. 59v.
} 
Antonio da C ruz também faz anal ogia do coração com um rei para ilustrar o domínio e a local ização do órgão no corpo. $\mathrm{N}$ a Recopilaçam de Cirurgia, Cruz afirma que " $O$ coração he a principal parte das de dentro do peito, 0 qual é principio da vida, \& assim como Rey, está no meio do peito (...)" ${ }^{\prime 16}$.

No poema intitulado "M icrocosmographia, e D escripção do M undo Pequeno, que é o H omem", de André $\mathrm{F}$ alcão de Resende, composto com base em tratados anatômicos, o coração é referido como uma figura de grande autoridade e dignidade, governando a todos no "edifício" ao qual o corpo humano é comparado ${ }^{17}$. 0 coração é o primeiro órgão que o protagonista do poema escol he encontrar na sua viagem pelo interior do corpo humano. F unções de governo do cérebro também são referidas, mas remetendo à imagem do filósofo, expressando idéia platônica, cara aos humanistas ${ }^{18}$.

A cabeça e o cérebro são por vezes associados à noção de rei, nos tratados portugueses, mas de uma forma diferente das anal ogias entre este e 0 coração. U m exemplo ocorre na dedicatória a D. João III de Problematum libri quinq, de Antonio L uiz. $O$ autor faz referência à sociedade portuguesa como um corpo, e ao rei, como a cabeça, afirmando que "os reis favorecem os vassal os como a cabeça o faz em relação aos demais membros" ${ }^{19}$. T homaz Rodrigues da Veiga usa imagem similar na dedicatória de sua Opera omnia in Galeni libros edita a D. Sebastião, caracterizado como "a cabeça de tantos povos" ${ }^{20}$. N estas passagens, não é o corpo ou uma de suas partes que são enfocados. A cabeça é o objeto ao qual o rei, foco das formulações, é comparado, num sentido inverso ao das imagens envolvendo o coração ${ }^{21}$. Além dis-

\footnotetext{
${ }^{16}$ Recopilaçam..., op. cit., p.32.

${ }^{17}$ M icrocosmographia (Com outros poemas), L isboa, s/e, 1865?, C anto II, 9, p. 23. Para análises do poema, ver L uis de Pina, A Cultura Anatómica em Portugal no Século XVI ea 'M icrocosmografia' deAndréF al cão deR esende, Coimbra, CoimbraE ditora, 1946; e "As 'Anatomias' de Ávila (1542) e M onserrate (1550) e a 'M icrocosmografia' de F alcão de Resende", Separata do J ornal do M édico, 41, 1942.

${ }^{18}$ M icrocosmographia , C anto II , 20-24. Análise das formas de circulação e da importância das idéias humanistas no contexto aqui estudado encontra-se em Bellini, "Representations of the H uman Body in Sixteenth-Century Portugal", Tese de D outoramento, University of E ssex, Colchester, Inglaterra (mimeo.), 1992, esp. cap. 4.

${ }^{19} \mathrm{~L}$ isboa, L uís R odrigues, 1539.

${ }^{20} \mathrm{~L}$ yon, Petrum L andry, 1587.

${ }^{21}$ Análise das implicações da posição de certos termos, como referência, em comparações, é feita em Arber, "Analogy..." op. cit., M ontagu (E d.), Studies and E ssays..., op. cit., p. 223.
} 
to, é a cabeça, e não o cérebro, que é mencionada. Pode-se afirmar que as imagens têm uma relação com a concepção gal ênica da preeminência do cérebro, mas apenas indiretamente.

U m outro exemplo, no qual a imagem do rei é associada à cabeça ou ao cérebro, encontra-se na discussão das funções deste último em D e Re M edica Opera. L uiz aponta como correta a concepção gal ênica do cérebro como centro dos sentidos, com o qual os órgãos dos sentidos se comunicam. Concluindo seu argumento, afirma: "o cérebro, encontrando-se na cabeça como no lugar de um grande rei, mantém o princípio da alma, tendo os sentidos em torno de si, como guarda-costas. A cabeça é para o homem o que o céu é para o universo; este é a morada dos deuses, aquela a morada da razão" 22. $U$ ma vez mais, tudo indica que $L$ uiz, tendo partido de um texto de $G$ aleno, expressa uma idéia própria. A inspiração para a analogia parece ter-se originado em DePlacitis H ippocratis et P latonis, mas ela tem um sentido específico no texto de $L$ uiz. A imagem foi inicialmente formulada por Platão ( $L$ eis, 964) ${ }^{23}$ e era de uso comum no tempo de G aleno, que a cita como não sendo prova adequada de que o cérebro abrigava a parte central da alma:

Porque o cérebro, como o Grande R ei, habita a cabeça como uma acrópolis, isto não necessariamente implica que a parte mais importante da al ma encontra-se no cérebro; nem porque o cérebro tenha os sentid os em torno dele como guarda-costas; ou mesmo se se afirmasse que, como o céu está para o universo, a cabeça está para o homem, e que, desta forma, como o primeiro é a morada dos deuses, o cérebro é a morada da faculdade racional (...) um conhecimento preciso não pode fundar-se em tais afirmações (... ${ }^{24}$.

Galeno também critica o uso desta analogia como prova da posição de governo do cérebro no corpo, no L ivro O ito de DeU su Partium²5.

Além da sua relação com as idéias de Galeno e Platão que, conforme foi observado anteriormente, é mais complexa que a simples afiliação, as imagens políticas encontradas nos tratados médicos portugueses associam-

\footnotetext{
${ }^{22}$ DeRe Medica..., op. cit., fol. 76r.

${ }^{23} \mathrm{~T}$ heD ialogues of P lato Translated into E ngli ish, com análises e introduções de Benjamin J owet, Oxford, Clarendon Press, 1892, 5 vols., vol. 5.

${ }^{24}$ On the D octrines..., op. cit., L ivro II 4.17-18, p. 121.

${ }^{25} \mathrm{O}$ n the U seful ness of the Parts of the B ody, T radução do grego com introdução e comentário por M argaret Tallmadge M ay, Ithaca, N ew York, Cornell U niversity Press, 1968, 2 vols., L ivro Oito [l, 445].
} 
I magens do corpo esaber médico em Portugal no sécul o XVI

se a representações nos textos de Aristóteles. E m D eP artibus A nimalium III .7 [670 a 20], o coração é descrito como "a cidadela do corpo" 26. E m Parva Naturalia III [469 a 5-10], A ristóteles afirma que o coração "tem controle supremo". E le também faz referência ao coração como "o órgão dominante" e "o órgão supremo dos sentidos" 27.

Por mais que o uso, por pensadores antigos, da imagem do rei para expressar lugares de comando tenha influenciado os autores portugueses, é plausível supor que esta imagem tinha significado especial no Portugal renascentista, visto que ocorre freqüentemente em diferentes tipos de texto. A palavra "rei" está entre os substantivos mais freqüentes em Os L usíadas, de C amões, aparecendo 230 vezes, menos vezes apenas que os termos "gente" e "terra" 28.

A idéia de um órgão como um rei implica a do corpo como um organismo social, encontrada em obras portuguesas do período, como o R etrato del P erfecto M edico, de H enrique J orge H enriques ${ }^{29}$; a "M icroscosmographia", de $\mathrm{F}$ alcão de Resende ${ }^{30}$; e a R opicapnefma, de J oão de Barros ${ }^{31}$. Afonso R odrigues de Guevara, com base em Galeno, descreve a função do fígado e sua relação com os demais órgãos da nutrição por meio de imagens sociais. Segundo o autor, o fígado é o principal entre os órgãos da nutrição, que Ihe

${ }^{26}$ T heWorks of AristotleTranslated into E nglish, Ed. William D avid R oss, Oxford, s/e, 1952-1963, 12 vols., vol. 5.

${ }^{27}$ Idem, vol. 3.

${ }^{28}$ A. G. Cunha (O rg.), Í ndice Analítico do Vocabulário de Os L usíadas, R io de Janeiro, Instituto N acional do L ivro; M inistério da E ducação e Cultura, 1966, 3 vols.

${ }^{29}$ Salamanca, R enaut I mpressores, 1595, pp. 208-209.

${ }^{30}$ M icrocosmographia , op. cit., Canto II, passim.

${ }^{31} \mathrm{~L}$ isboa, 1532, R eprodução fac-similada, L eitura modernizada, notas eestudo del srael $\mathrm{S}$. R evah, 2 vols., L isboa, I nstituto N acional de Investigação C ientífica, 1983, pp. 32-33. Yvonne D avidPeyre sugere que metáforas sociais do corpo, comuns na Península I bérica no século XVI, se deviam à grande circulação da Theologia Naturalis, sive L iber creaturarum (1487), do filósofo e médico espanhol R aymond Sebond (?-1432), que trabalhou naF rança. "L aAlegoria del Cuerpo H umano en la Península I béricadel Siglo de O ro", Asclepio (Archivo I beroamericano de H istoria de la M edicina y Antropología M édica), vol. 28, 1976, pp. 243-254, pp. 243-244. Sobre a influência do Liber creaturarum, de Sebond na Ropicapnefma, ver I. S. Révah, "L e colloque R opicapnefma de J oão de Barros. Gènese, structure et technique" , B ulletin H ispanique64 (bis), 1962, pp. 572-592, pp. 576-577. I magens sociais em representações do corpo na Península I bérica podem, ao menos em parte, ter derivado diretamente dos textos de $G$ aleno. Exemplo disto é a representação, discutida a seguir, da relação do fígado com os demais órgãos da nutrição, por Afonso Rodrigues de Guevara. 
são submetidos "como servos" ${ }^{32}$. Como observam Temkin e L loyd, o uso de analogias políticas e sociais para descrever ou explicar fenômenos naturais em geral expressa a tentativa de compreender tais fenômenos da perspectiva da idéia de ordem ${ }^{33}$. D esta forma, pode-se dizer que as imagens sociais e políticas que se encontram nos textos portugueses indicam a tentativa, por parte dos seus autores, de apresentar uma visão sistemática do organismo humano, compreendido como um todo organizado, por analogia com a ordem social. E stas imagens, além disto, expressam concepções hierárquicas tanto do corpo quanto do organismo político. $\mathrm{N}$ a sua base, está a idéia de que ambos os corpos constituem a união de elementos distintos em função e significado ${ }^{34}$.

0 rei representa o princípio de governo $0^{35}$, um significado evidentemente expresso nas imagens examinadas acima. D esta forma, as representações do coração como um rei podem ter sido um meio pelo qual afiliações ao escolasticismo aristotélico foram expressas num contexto onde os autores se declaravam seguidores de conceitos genuinamente gal ênicos. Como notal an M aclean, "estratégias lingüísticas podem servir para resolver contradições e deslocamentos no pensamento; podem também atuar nele como forças conservadoras" ${ }^{36}$. É significativo que estas representações ocorram principalmente nos textos dos autores mais expostos às idéias de Aristóteles. De Re M edica Opera, de Antonio $L$ uiz, foi escrita nas primeiras décadas do século XVI (foi publicada em 1540). L uiz ensinou as doutrinas de Aristóteles na

\footnotetext{
${ }^{32}$ I n pluribus ex ijs quibus Galenus impugnatur ab Andrea Vesal io B ruxe ési in cõstructione\& usu partium corporis humani, defensio, C oimbra, J oão de Barreira, 1559, p. 250. E sta e outras metáforas sociais encontram-se na análise de $\mathrm{G}$ al eno dos instrumentos da nutrição. Ver $\mathrm{O}$ the $U$ sefulness of the Parts..., op. cit., L ivro Q uatro [I, 195-197], pp. 204-205.

${ }^{33}$ O wsei Temkin, "M etaphors of H uman Biology" , R. C. Stauffer (E d.), Scienceand Civilization, M adison, U niversity of Wisconsin Press, 1949, pp. 167-194, esp. p. 192; L loyd, Polarity and Analogy..., op. cit., pp. 225-226. Para relações da noção de realeza com a de ordem social ou ordem cósmica no pensamento grego antigo, ver R. Goodenough, "T he Political Philosophy of H ellenistic Kingship", YaleClassical Studies I, 1928, pp. 55-102.

${ }^{34} \mathrm{~L}$ eonard Barkan, $\mathrm{N}$ ature's Work of Art: TheH uman B ody as I mage of the World, $\mathrm{N}$ ew $\mathrm{H}$ aven e L ondres, Yale U niversity Press, 1975, pp.78-79.

${ }^{35}$ Ver, entre outros, J. E. Cirlot, A Dictionary of Symbols, L ondres, R outledge and Kegan Paul, 1978, pp. 167-168.

${ }^{36}$ The R enaissance $\mathrm{N}$ otion of Woman: A study in the fortunes of scholasticism and medical science in E uropean intellectual life, Cambridge, Cambridge U niversity Press, 1987, p. 90.
} 
U niversidade de Coimbra ${ }^{37}$. A R ecopilaçam deCirurgia, de Antonio da C ruz, funda-se extensivamente em conhecimento médico medieval ${ }^{38}$.

O utras idéias com as quais o coração e o cérebro são associados nos tratados médicos contribuem para a compreensão da importância relativa destes órgãos. T rata-se das noções gal ênicas de viver ee benevivere ("estar vivo" e "viver bem"). Segundo Galeno, há três tipos de utilidade das partes do corpo: manter a vida, tornar a vida melhor e preservar a raça. As partes ligadas à manutenção da vida devem ser consideradas essenciais, com as demais decrescendo em importância, na medida de sua distância funcional em relação às primeiras ${ }^{39}$. Associações do coração com manter a vida e do cérebro com viver bem ocorrem diversas vezes na O pera omnia in Galeni libros, de Rodrigues da Veiga. U m exemplo é a passagem em que o autor discute qual é o órgão mais importante no corpo. E le argumenta que, se a preeminência for definida em termos da manutenção da vida, o coração é mai s importante. Se, por outro lado, o critério for "a dignidade de função", então o cérebro éo maisimportante entre os dois órgãos, "namesma medida em que sentir e movimentar-se, quer dizer, viver bem émelhor que simplesmente viver" 40.

Antonio $L$ uiz também faz referência à noção galênica dos três tipos de utilidade das partes, concluindo que as mais importantes são as necessárias para manter a vida ${ }^{41}$. A associação ocorre ainda em D e universa mulierum M edicina, de Rodrigo de Castro, quando o autor discute a ordem na qual os órgãos principais do corpo são gerados no embrião ${ }^{42}$. C astro discorda das razões, segundo ele apontadas por $\mathrm{G}$ aleno, pelas quais os principais órgãos são gerados em tempos diferentes, e também da conclusão de que o cérebro é gerado após o coração ${ }^{43}$. M as sua menção às noções de vivere e bene vivere

\footnotetext{
${ }^{37}$ Alberto da R ocha Brito, A F aculdade de M edicina no Século XVI , F igueira da F oz, T ipografia Popular, 1937, pp. 5-15; J osé Sebastião da Silva D ias, Os D escobrimentos ea Problemática Cultural do Século XVI , L isboa, E ditorial Presença, 1988, pp. 43-44.

${ }^{38}$ Bellini, "M edicina e saber erudito...", op. cit., Seção III.

${ }^{39}$ On the U sefulness of the Parts..., op. cit., L ivro Seis [I, 318], p. 292.

40 Opera omnia..., op. cit., p. 47. Ver também pp. 24 e 356.

${ }^{41}$ D e R e M edica..., op. cit., fols. 54v-55r.

${ }^{42}$ D euniversa mulierum M edicina..., op. cit., Pars Prima T heorica, $\mathrm{H}$ amburgo, Philippe de $\mathrm{O}$ hr, 1603, p. 96.

${ }^{43} \mathrm{~A}$ idéia de que o cérebro é gerado depois do coração e de que ambos os órgãos são gerados após o fígado não se encontra em D eU su Partium. Galeno apenas argumenta que o fígado é
} 
reforça a idéia de que estas eram correntes na época. Sugestão de que o cérebro era menos essencial para manter a vida é ainda feita na definição de corpo humano de Antonio da Cruz: "hum composto de muitos, $\&$ diversos membros, \& particulas, ornado de razão" 44 .

A relação entre o coração e a vida humana é ainda sugerida num desenho de $\mathrm{F}$ rancisco de $\mathrm{H}$ olanda, intitulado "A criação de Adão do pó da terra". N ele, o criador é representado dando vida ao primeiro homem, na forma de raios partindo da sua boca e mãos e dirigindo-se a partes do corpo de Adão. U $m$ feixe de raios liga a boca de $D$ eus ao coração de Adão, um enorme coração, o único órgão interno mostrado no seu corpo ${ }^{45}$. A imagem possivelmente representa a idéia neoplatônica do amor como o motivo pelo qual $D$ eus difunde sua essência no mundo e que, inversamente, faz com que suas criaturas procurem reunir-se a ele ${ }^{46}$. E ntretanto, observando-se a forma como Adão é representado receben do a vida, é difícil não relacioná-la com as idéias aqui exploradas.

Ainda um outro tipo de conexão simbólica pode iluminar as razões da preeminência do coração sobre o cérebro, nos textos médicos portugueses. Trata-se da idéia do coração como sede de uma das três partes da alma, na concepção de Platão e G aleno - a alma espiritiva - e seus atributos de coragem e bravura, uma idéia bem estabelecida na literatura ibérica. $\mathrm{Na} O$ pera omnia in Galeni libros, de Veiga, estes atributos são tidos como sinais de um coração quente na correta medida ${ }^{47}$. H á diversas referências ao coração como sede da bravura, na literatura portuguesa da época. J oão de Barros, no Dialogo sobre preceptos moraes, menciona F ortal eza, "hua virtude q faz a quem a tem, nã ser temeroso de honesta morte", como uma das virtudes tendo a

\footnotetext{
"muito forte desde o início da sua geração, porque o encéfalo, o coração e os instrumentos que crescem destes têm que se beneficiar das veias; sem sangue estes não podem ser gerados ou crescer, enquanto, antes de estarem prontos, o fígado e as veias pouco necessitam das artérias e nada dos nervos". On the U seful ness of the Parts..., op. cit., L ivro Quinze (II , 359-360], pp. 669670.

${ }^{44}$ Recopilaçam..., op. cit., p. 14.

${ }^{45}$ Reproduzido em Sylvie D eswarte, As I magens das I dades do M undo deF rancisco deH olanda, L isboa, I mprensa N acional - C asa da M oeda, 1987, figura 18.

${ }^{46} \mathrm{E}$ rwin Panofsky, Studies in I conol ogy: H umanistic Themes in theArt of the Renaissance, N ew York e L ondres, H arper and R ow, 1972, p. 141.

${ }^{47}$ Opera omnia..., p. 50.
} 
potência espiritiva da alma como centro48. $\mathrm{Na}$ " M icrocosmographia", $\mathrm{F}$ alcão de Resende descreve al egoricamente o coração como "Parecendo mancebo ainda e valente" 49 . A associação tem ênfase particular em Os L usíadas. 0 termo coração é, no poema, por vezes utilizado para designar a própria coragem e, por vezes, aparece como sede desta ${ }^{50}$.

As relações simbólicas acima encontram-se na poesia épica espanhola, escrita séculos antes de Os L usíadas. Colin Smith, em estudo sobre o papel de partes do corpo como referências simbólicas nos épicos medievais espanhóis, nota que o conceito de bravura está presente na própria formação da palavra "corazón", relacionada à noção do coração como sede da coragem. 0 autor, além disto, aponta a afiliação etimológica dos termos "courage" (no inglês e francês) e "corage" (no espanhol) à palavra latina designando "coração" ("cor") 51 .

Segundo Smith, o coração é o único órgão, entre as partes externamente não-visíveis do corpo, com significado simbólico nos épicos espanhói $5^{52}$. 0 autor nota ainda a ausência de frases com o termo "cabeza" na literatura por ele analisada ${ }^{53}$. Isto não se verifica em Os L usíadas, em que a palavra "cabeça" aparece muitas vezes, apesar de menos freqüentemente que "coração" ${ }^{44}$. N ão há frases com a palavra "cérebro" no épico português, nem 0 termo "cabeça" é usado para designar "cérebro" diretamente. N o entanto, em cinco passagens do poema, "cabeça" expressa metaforicamente a mais importante parte de um todo $0^{55}$, um significado que parece estar relacionado à noção galênica da supremacia do cérebro no corpo, mas indiretamente. U ma destas passagens consiste numa metáfora semelhante às encontradas nas

\footnotetext{
${ }^{48} \mathrm{D}$ ialogo deJ oam de B arros com dous filhos seus, sobrepreceptos moraes, em modo de jogo, L isboa, J oão de Barreira, 1563, s/p.

${ }^{49}$ M icrocosmographia, op. cit, Canto II, 8 e 13.

${ }^{50}$ Cunha (O rg.), Índice..., op. cit., vol. A, Cantos X, 20 e 31; II , 59; I , 89; III, 108; IV, 21 e 29; V, 38 e 74; VI, 64

51 "L a F raseologia 'F ísica' del L enguage É pico", Smith, Estudios cidianos, M adrid, Cupsa E ditorial, 1977, pp. 219-289, pp. 271-272.

${ }^{52}$ Idem, p. 281. D evo esta idéia ao professor E vanildo Bechara, a quem agradeço ainda pela gentileza de me enviar cópia do artigo de Smith, citado aqui.

${ }^{53}$ Idem, p. 263.

${ }^{54}$ Ver Cunha (Org.), Índice..., op. cit., vol. A, p. 111.

${ }^{55}$ Cantos II, 84; III, 17; III, 20; VII, 22; X, 123.
} 
dedicatórias de Antonio L uiz, em Problematum libri, e de Veiga, na Opera omnia in Galeni libros, aos reis J oão III e Sebastião, respectivamente, já referidas neste artigo, nas quais é feita analogia da sociedade portuguesa a um corpo, de que o rei é a cabeça: “E porque he de vassalos, o exercicio, / Que os membros tem regidos da cabeça" ${ }^{56}$.

É lícito supor que a preponderância do coração nos textos médicos portugueses se relaciona, além de outros fatores discutidos neste artigo, à importância simbólica deste órgão na literatura. As associações semânticas, brevemente apresentadas acima, com toda probabilidade tiveram especial eco em Portugal no século XVI, onde as viagens de descobrimento fizeram emergir um espírito épico. E ram comuns, no período, as referências à ousadia eà bravura dos portugueses em levar a cabo as explorações marítimas ${ }^{57}$. 0 conhecimento médico em Portugal, nos começos da época moderna, integrava este contexto cultural amplo, em que os diferentes saberes não estavam separados uns dos outros. U m indício da relação aqui proposta é o comentário de Veiga quanto aos sinais de um coração quente: "coragem e ousadia em enfrentar tarefas difíceis" 58 , um adendo, ao que parece, criado pelo autor.

Sumariamente, conforme discutido acima, diferentes tipos de razões se combinam para explicar uma certa preeminência do coração sobre o cérebro, nos tratados portugueses sobre biologia humana. E m primeiro lugar, esta expressa a permanência, entre pensadores que se declaravam seguidores de Galeno, de idéias aristotélicas e da prática escolástica de procurar conciliar as opiniões das autoridades. E $m$ segundo lugar, indica uma ênfase na idéia de manutenção da vida, ao invés dos "menos essenciais" sentidos e razão, uma visão que deriva de uma interpretação particular do pensamento galênico. E m terceiro lugar, a valorização do coração possivelmente se deve ao influxo, sobre as obras médicas, de fatores externos ao debate intelectual

\footnotetext{
${ }^{56}$ Canto II, 84.

${ }^{57}$ Isto é apontado por diversos historiadores que estudaram a cultura portuguesa no tempo das viagens marítimas. Um quadro geral deste contexto é apresentado em Bellini, "N otas sobre Cultura, Política e Sociedade no M undo Português do Século XVI", Tempo, vol. 7, R io de Janeiro, 1999, pp. 143-167. Análise interessante e bem documentada da associação aqui enfocada encontra-se em R eger $\mathrm{H}$ ooykaas, $\mathrm{H}$ umanism and theVoyages of D iscovery in 16 th Century PortugueseScienceand L etters, separata de M ededelingen D er K oninklijkeN ederlandseAkademieVan Wetenschappen, Aft. L etterkunde, 42 / 4, A msterdam eN ew York, N oord-H ollandsche U . M ., 1979, pp. 21-24.

${ }^{58}$ Opera omnia..., op. cit., p. 50.
} 
na medicina. D eriva da associação deste órgão, através da concepção galênica do coração como centro da potência espiritiva da alma, com a atmosfera épica que emergiu, no Portugal quinhentista, com as viagens de descobrimento e guerras de conquista.

A relevância dada ao coração e suas funções de manter a vida e constituir o centro da coragem e da bravura remete a uma ênfase no vigor físico, em detrimento da potência mental, nos seres humanos. Há um inegável contraste entre esta ênfase e o apreço do platonismo humanista pela natureza intelectual do homem. E ste é outro aspecto que indica a complexidade das relações entre a adoção de novas idéias e a permanência de antigos pressupostos com respeito à natureza humana, atestando a imbricação de formas de pensamento medievais e renascentistas no contexto português.

Por fim, resta refletir sobre o que as representações examinadas indicam quanto ao desenvolvimento da observação empírica, no saber médico em Portugal. E m sua maior parte, estas representações não podem ser qualificadas como expressão de uma abordagem empírica mais consistente. Algumas delas sugerem a influência de modos de pensar mágicos ou ocultos, a exemplo da concepção do coração e do cérebro como sedes de potências específicas da alma, e as associações entre condições físicas destes órgãos (quente / frio, úmido / seco) e características psicológicas. E ste é também o caso da tendência dos autores a considerar que o argumento analógico serve de demonstração de fenômenos no corpo humano. U m exemplo é a aceitação, por Antonio L uiz, da anal ogia entre o coração e um rei no comando de um exército, como demonstração de que o coração não é o último órgão a morrer, no corpo.

D e modo geral, como foi apontado em diferentes momentos neste artigo, as imagens analisadas indicam a estreita ligação dos autores médicos portugueses com a tradição de comentário, e sua dependência em relação aos textos das autoridades na área, ao invés da observação empírica. A despeito destas características comuns, diferentes usos do argumento analógico sugerem um espectro, embora não muito variado, de atitudes com respeito ao saber médico. $N$ um extremo está Antonio L uiz, cujas obras são as mais ricas em imagens e pensamento analógico, e que pode ser considerado o mais distante da observação empírica e da prática médica, entre os doutores estudados. N outro extremo, encontra-se Afonso Rodrigues de Guevara, que faz uso de analogia de forma mais limitada, e diferente em natureza, que L uiz. E ste último, possivelmente sob influência da ênfase humanista em 
retórica, parece considerar as qualidades literárias de artefatos lingüísticos como mais importantes que o seu potencial heurístico e ilustrativo, de um ponto de vista mais científico. Ao invés de ter como objetivo central explicar objetos e fenômenos, suas imagens parecem ser, em grande medida, ornamentos de estilo. Não parece ser o caso de Guevara, que recorre à analogia principal mente para elucidar funções ou descrever a forma de partes do corpo por meio de comparação com objetos similares, tendendo a abandonar a comparação tão logo cessem as si milaridades. Seu uso do procedimento analógico pode ser exemplificado pela afirmação, fundada em $\mathrm{G}$ aleno, de que as fibras externas dos músculos intercostais se cruzam como a letra grega $X$ 59; ou a comparação, também com base em $G$ aleno, entre processos digestivos no estômago e no fígado e a fermentação do vinho $0^{60}$. N estes e noutros exemplos, Guevara não segue propondo correspondências entre os objetos comparados. Parece menos preocupado com os atributos poéticos de artefatos lingüísticos do que com suas qualidades explanatórias. Tudo indica que Guevara era o mais independente, em relação aos textos das autoridades, entre os autores médicos em Portugal, no século XVI ${ }^{61}$. Com base nos usos diversificados do argumento analógico, talvez se possa afirmar que, no decorrer do período investigado, ocorre uma mudança da predominância de influências humanistas, associadas à tendência à preservação da síntese escolástica, até um ponto em que uma certa atenção empírica coexiste com as formas de abordagem anteriores.

Por outro lado, as diferenças acima devem ser vistas em termos relativos, visto que tanto $G$ uevara quanto $L$ uiz se baseavam extensivamente nos escritos de $\mathrm{G}$ aleno. J unto com outros autores no seu contexto, eles estavam primeiramente ligados a uma tradição de comentário textual, com a observação empírica tendo um papel secundário. Como grande parte dos homens de letras do R enascimento, os médicos portugueses atuavam centralmente de acordo com modos de pensar herdados dos seus predecessores.

\footnotetext{
${ }^{59}$ I n pluribus..., op. cit., pp. 88 e 93. E sta comparação ocorre em Galeno, On Anatomical P rocedures, Tradução, intodução e notas de C harles Singer, L ondres e N ew York, T he Wellcome H istorical M edical M useum; Oxford U niversity Press, 1956, L ivro V, C ap. 4 (502), p. 132.

${ }^{60}$ In pluribus..., op. cit., p. 254. Para afonte original desta comparação, ver $G$ aleno, 0 n theU sefulness of the Parts..., op. cit., L ivro Q uatro [I, 197-198], pp. 205-206.

${ }^{61}$ M aximiano L emos, H istória da M edicina em P ortugal: D outrinas el nstitui ções, 2 vols., L isboa, M anoel Gomes, 1899, vol. 1, pp. 221-223; S. Costa Santos, 0 I nício da E scola de Cirurgia do H ospital Real deTodos os Santos, 1504-1565, L isboa, 1925, pp. 23ss.; R ocha Brito, A F aculdade.., op. cit., pp. 56-62.
} 